\title{
A fala de adolescentes marginais em Belo Horizonte
}

\author{
Vera Lúcia Menezes de Oliveira e Paiva \\ Universidade Federal de Minas Gerais
}

\section{Abstract}

This paper discusses some research results on sex differences in the speech of homeless adolescents in Belo Horizonte. The study showed that male speakers use more standard forms than female speakers, although the inicial hypothesis predicted that groups with a great many characteristics in common would present little differences concerning prestige forms. 


\section{INTRODUGAO}

1 hipótese de que "as mulheres adaptam-se mais às formas de A prestígio do que os homens" tem sido comprovada praticamente $11 \mathrm{em}$ todas as investigações, segundo Dittmar (1976:237). Pesquisas como as de Labov (1966) em Nova York, Trudgill (1974) na Noruega, Macaulay (1978) em Glasgow, Cheschire (1982) em Reading, na Inglaterra, e Milroy, J. \& Milroy, L. (1978) em Belfast, realmente demonstram que as mulheres são mais fiéis à linguagem padrão do que os homens. Uma discussão geral sobre linguagens masculina e feminina pode ser encontrada em Aebischer \& Forel (1991) e também em Coates (1986). Ao enfatizar a hipótese acima, Coates (1986) menciona, além das pesquisas já citadas, os trabalhos de Newbrook em West Wirral e de Romaine em Edinburgh.

Um dos trabalhos de particular interesse para a nossa discussão é a pesquisa de Cheschire (1982) que analisou a variante do inglês não-padrão falado em Reading, tomando como informantes adolescentes de ambos os sexos de classe social baixa. $O$ estudo conclui que as formas não-padrão são mais usadas pelos informantes do sexo masculino.

Cheschire (1982) demonstrou que os grupos diferenciavam-se não apenas quanto ao sexo, mas também quanto à sua estruturação interna. Os rapazes andavam em bando e realmente formavam um grupo, enquanto as moças tinham tendência a se agrupar em pares. Dentro do grupo das moças, foram observados comportamentos diametralmente opostos. Uma das meninas, por exemplo, matava aula com frequiência, roubava dos pais ou de lojas e tinha comportamento bastante liberado com rapazes, enquanto que uma outra não falava palavrões, não matava aula, não saía com rapazes, além de se achar socialmente superior. Os rapazes cometiam pequenos 
furtos, colocavam fogo no playground e em casas abandonadas, cometiam atos de vandalismo contra edifícios e cabines telefônicas e, normalmente, carregavam armas. As moças colecionavam fotografias, posters e discos de seus ídolos, passavam menos tempo na rua do que os rapazes e eram responsáveis por pequenas tarefas em casa. Tanto os rapazes quanto as moças gostavam de luta corporal, normalmente nos playgrounds, mas as meninas se envolviam menos em lutas e falavam menos palavrões do que os meninos. Estas variáveis interferiram nas pesquisas, pois o grupo das meninas era bastante diferente do grupo dos meninos. Segundo Cheschire $(1982: 109)$,

como as meninas não pertenciam a um grupo muito coeso e não tinham sistema ou valores culturais definidos, não foi possível medir sua lealdade vernacular por meio de índices culturais. ${ }^{1}$

Apesar de reconhecer a interferência dessas diversas variáveis, Cheschire (1982) aponta o sexo como a principal marca diferenciadora da fala dos adolescentes de Reading, o que nos leva a olhar seus dados com uma certa reserva. Seria a variável sexo o fator principal de diferenciação? O mesmo resultado estaria presente em grupos onde houvesse controle das outras variáveis?

\section{HiPótese}

Em face das dúvidas trazidas pela pesquisa de Cheschire (1982), elaborou-se a seguinte hipótese: HAVERÃ POUCA OU NENHUMA VARIAÇÃO QUANTO AOS DESVIOS DAS FORMAS DO PORTUGUES-PADRÃO EM GRUPOS DE SEXOS OPOSTOS QUE TENHAM EM COMUM UM GRANDE NUMERO DE OUTRAS CARACTERISTICAS FORTEMENTE MARCADAS. Esta hipótese deveria ser testada em grupos de adolescentes abandonados que vivessem em bandos e que tivessem comportamento considerado marginal. O ponto diferenciador da pesquisa já mencionada consistiria na procura de informantes do sexo feminino que tivessem características bastante semelhantes às do sexo masculino. 


\section{A ESCOLHA DOS INFORMANTES}

Solicitou-se permissão à Fundação do Bem-Estar do Menor, FEBEFM, de Belo Horizonte para entrevistar grupos de adolescentes de ambos os sexos que tivessem em comum as seguintes características:

- vida na rua e em bandos;

- pouco ou nenhum contato com a família;

- idades aproximadas;

- várias ocorrências policiais relacionadas a furto e/ou assalto.

Vários prontuários de adolescentes considerados irrecuperáveis foram separados e cuidadosamente examinados. Além das características previamente estipuladas para a pesquisa, foram selecionados informantes, de ambos os sexos, que apresentavam algumas das seguintes características:

- família desintegrada, apresentando um ou mais dos seguintes traços: pais separados; pai, mãe ou padrasto alcoólatra; irmãos de pais diferentes; desconhecimento da identidade do pai; desconhecimento do paradeiro do pai ou da mãe; irmãos dispersos;

- vivência de situação de violência: espancamento pela mãe ou pelo pai; testemunha de espancamento da mãe pelo pai ou padrasto;

- fuga de casa e ou abandono pela família;

- envolvimento com drogas tais como cocaína, maconha, cola, e xarope;

- registro, nos prontuários, de fugas da FEBEM;

— passagem pela polícia.

Foram selecionados 6 elementos de cada grupo. Um dos meninos recusou-se a participar e o mesmo aconteceu com uma das meninas, que, no entanto, juntou-se ao grupo ao longo da entrevista e participou da parte final da gravação. A maioria deles não possuía registro de nascimento $e$ as idades eram presumidas. Nenhum dos informantes estava estudando e havia um menino que havia estudado até a $4^{3}$ série e uma menina que cursava a $5^{3}$, segundo registro nos prontuários. O restante dos informantes não 
possuía nenhuma ou quase nenhuma escolaridade, quando muito haviam estudado até ${ }^{\circ} 1^{\circ}$ ou $2^{\circ}$ ano do primeiro grau com alto indice de repetência.

\section{PERFIL DOS INFORMANTES}

A autorização da F'EBEM foi dada sob condição de se manter o anonimato dos informantes, portanto os mesmos serão descritos de acordo com um número.

\subsection{Grupo dos Meninos}

Informante 1 - Nasceu em Betim, cidade próxima a Belo Horizonte. Tem 17 anos e, desde que a mãe morreu, passou a ir para a rua. Mora na rua e só vai à casa do pai a passeio. Faz uso de todos os tipos de tóxico, furta e foge freqüentemente da FEBEM. Cursou até a $4^{a}$ série do primeiro grau. Tem 4 irmãos.

Informante 2 - Nasceu em Belo Horizonte. Idade presumida de 11 anos. Foge de casa porque apanha da mãe. Faz uso de vários tipos de tóxico, cheira cola e já foi preso várias vezes por furto, vadiagem e arrombamento. Foge freqüentemente da FEBEM. Tem 4 irmãos.

Informante 3 - Nasceu em São Paulo e veio para Belo Horizonte aos nove anos. Tem 15 anos presumidos. órfão de mãe, diz morar com o pai, mas vive na rua. Não tem escolaridade. Cheira cola, fuma maconha e já foi preso por furto e vadiagem. Foge sempre da FEBBEM. Tem 9 irmãos.

Informante 4 - Nasceu em Belo Horizonte e tem 11 anos. Vive na rua, tem pai e madrasta. Sua mãe perdeu a guarda dos filhos por levar vida irregular. Não tem escolaridade. Cheira cola, fuma maconha e já foi preso por vários furtos. Foge sempre da FEBEM.

Informante 5 - Nasceu em Belo Horizonte e tem 13 anos presumidos. órfão de pai e a mãe pede esmolas. Cursou a $1^{*}$ série do $1^{\circ}$ grau e vive na rua há 3 anos. Cheira cola, fuma maconha e já foi preso por furto e vadiagem. Foge sempre da FWBEM. 


\subsection{Grupo das Meninas}

Informante 1 - Nasceu em Pirapora, Minas Gerais, e tem 12 anos. Cursou o $1^{\circ}$ ano do $1^{\circ}$ grau e foi reprovada. Seus pais são alfabetizados, mas nenhum dos seus 7 irmãos ultrapassou 0 $1^{\circ}$ ano primário. O padrasto é alcoólatra. Cheira cola e gosta da vida de rua, por isto foge da FEBEM com frequiência. Chupou dedo durante toda a entrevista e chorou quando provocada pelas companheiras.

Informante 2 - Nasceu em Belo Horizonte e tem 11 anos. A mãe, analfabeta e alcoólatra, é freqüentemente espancada pelo companheiro. Atualmente está desaparecida. A informante furta e tem um irmão interno na FEBEM. Sua ficha diz que ela cursa a $5^{a}$ série, mas a informante não confirmou a informação. Foge da FEBEMM com frequiência.

Informante 3 - Nasceu em Belo Horizonte e tem 11 anos. A mãe não trabalha e não tem residência fixa, além de ser alcoólatra e maconheira. Tem 4 irmãos de pais diferentes e um também é interno da FEBEM. Comete pequenos furtos e já se envolveu em furto de veículo com danos materiais. Já foi presa por tentativa de arrombamento e é tida como desordeira. Não possui escolaridade. Bebe e foge da FEBEM, liderando as informantes 1 e 2 .

Informante 4 - Nasceu em Ouro Verde, Minas Gerais, e tem 15 anos. Nunca foi à escola. $\overline{\mathbf{E}}$ mãe de uma menina que está em São Paulo. Seus pais são separados e seus irmãos estão dispersos. Furta e foge da FEBEM levando consigo colegas que obriga à prostituição para conseguir dinheiro para se alimentar. É viciada em tóxicos. Teve envolvimento com marginais. Obriga as companheiras da FEHBEM a trabalhar para ela.

Informante 5 - Nasceu em Governador Valadares, Minas Gerais, e tem 13 anos presumidos. A mãe foi abandonada pelo pai. Tem mais 8 irmãos, sendo um deles traficante de drogas e outro, com várias entradas na FEBEM. A informante fugiu para Belo Horizonte após brigar com a mãe e foi morar com uma tia. Atualmente não tem residência fixa e fica na rua. Ficou grávida no ano anterior, mas 
abortou espontaneamente. Já teve doença venérea, desmaia de vez em quando e toma remédio controlado. Nunca estudou. Furta, fuma maconha e foge da FEBEM com freqüência.

Informante 6 - Nasceu em Belo Horizonte e tem 16 anos. Filiação ignorada, tendo sido abandonada pela mãe. Vive em completo estado de abandono. Já foi presa por vadiagem, furtos, furto à residência, ameaça de agressão à faca e à paulada. com as colegas e foge da FEBEM, onde está desde os 4 anos. Apesar de não ter problemas mentais, incorporou a idéia de que "tem problemas de cabeça", idéia esta inculcada por uma freira da FEBEM de Ouro Preto, Minas Gerais (Esta informante participou apenas da parte final da gravação.)

\section{Metodo de Pesquisa}

As gravações foram feitas no dia 03 de agosto de 1988. O grupo dos meninos foi entrevistado pela manhã e o das meninas na parte da tarde. Os grupos foram chamados pela responsável de cada setor que lhes perguntava se eles gostariam de participar de uma pesquisa, colaborando com uma professora da universidade. Os internos ficaram curiosos e dispostos a participar e apenas um em cada grupo se recusou. Os grupos fizeram diversas perguntas à documentadora, receosos de que a gravação pudesse ser usada contra eles. Foi pedido a cada grupo que escolhesse o local da entrevista. As meninas escolheram uma sala e todas, incluindo a documentadora, sentaram-se no chão. Os meninos escolheram um campo de futebol, pois havia sol e estava um dia muito frio. No campo de futebol, havia um banco de cimento, mas a documentadora sentou-se no chão junto aos informantes. Neste momento ficou claro que o "paradoxo do observador" fatalmente ocorreria . Os meninos ficaram preocupados com a documentadora e insistiam para que ela se sentasse no banco para não sujar a roupa. A documentadora era uma estranha, uma professora, que eles estavam aceitando com admiração e boa vontade, mas a distância social iria fatalmente interferir na observação. Os meninos se policiaram e não usaram palavrões, enquanto as meninas tiveram reação oposta. Em um dado momento da entrevista, um menino chamou a atenção de 
um companheiro que teria falado um palavrão (não percebido pèla documentadora) e pediu para que ele respeitasse "a dona".

Segundo Milroy, L. (1987:40),

Apesar do desenvolvimento de técnicas especiais, o lingüista investigador, invariavelmente, encontrará o problema que Labov, adequadamente, denominou de "paradoxo do observador": a linguagem em uma comunidade só pode ser estudada através de coleta de grande volume de dados de fala espontânea em gravações de boa qualidade. Todavia, um estranho que tentar obter tais dados alterará dramaticamente a qualidade do fenômeno que está observando. ${ }^{2}$

Cheschire (1982:7-8) também chama a atenção para o problema do "paradoxo do observador" e lembra a estratégia de Milroy (1980), ao trabalhar com a técnica do "amigo do amigo" dentro de redes e explica a sua própria opção ao usar o método "long-term participant-observation." Nenhuma dessas técnicas, no entanto, por motivos óbvios, pôde ser usada, mas o gelo foi quebrado quando os informantes tomaram conhecimento de que o pai da documentadora havia passado parte de sua infância em uma instituição semelhante à FEBEM. Apesar de os dois grupos não terem feito perguntas sobre este fato, a informação parece ter contribuído para ganhar a confiança dos informantes. Quanto ao motivo da entrevista foi dito aos informantes que estava sendo feita uma pesquisa para saber como o povo brasileiro falava e que eles haviam sido escolhidos por não sofrerem a influência da escola, o que tornava a fala deles mais espontânea e natural.

\subsection{A Escolha do Assunto}

Perguntou-se aos dois grupos se eles queriam escolher um assunto para a conversa. Os meninos não apresentaram nenhum assunto e foi-lhes sugerido falar sobre uma situação de perigo que já tivessem enfrentado. A proposta foi aceita. A conversa com as meninas foi mais espontânea no início e a sugestão do mesmo tema só foi feita depois de algum material já ter sido gravado. Os dois grupos demonstraram satisfação em participar das gravações e de vez em quando solicitavam que a mesma fosse tocada para que eles pudessem escutar. 


\section{ANALISE DOS DADOS}

\subsection{Seleção do Corpus}

Foram gravados 45 minutos com os meninos e 60 minutos com as meninas. Uma das meninas que havia se recusado a participar juntou-se ao grupo trinta minutos depois do início da gravação. $\mathrm{Na}$ transcrição dos dados, foram obtidas 39 laudas na gravação dos meninos e 57 na das meninas. Optou-se por usar todo o material dos meninos e as 40 páginas iniciais da transcrição da gravação das meninas, pois cerca de uma folha continha apenas falas da documentadora e de uma funcionária da FEBEM que fora chamada para medicar uma menina.

\subsection{Seleção das Variáveis}

Uma variável marcante era o uso do vocabulário por parte das meninas que se distanciava muito do registro padrão. Porém, o fato de os meninos terem se policiado, chegando mesmo a ameaçar os companheiros para não usarem palavrões na presença da documentadora, fez com que esta variável fosse ignorada. Optou-se, então, por duas variáveis apenas: concordância verbal e concordância nominal.

A análise ficou restrita aos itens que apresentavam a ordem $\mathrm{SV}$, pois apenas duas ocorrências da ordem VS apareceram, tanto no discurso dos meninos quanto no das meninas, e todos sem marca de concordância. Os itens escolhidos apresentavam, como sujeitos, "nós", "eles", "a gente" e itens lexicalizados com marca de pluralidade na ordem SV. Foram ignorados, além dos sintagmas na ordem SV, os sintagmas com sujeito composto por pronome + item lexicalizado, como, por exemplo, "tava eu e meus colega". As repetições não foram contabilizadas quando apareciam em sequiência, como no seguinte exemplo:

Aí nós tava lá, né? aí chegou um menino que chama..., que chama Frei... nós tava... aqui é minha amiga de infância, como irmã. Aí tavo... tava ela, eu... nós tava tudo sentada lá fora, um tanto de menina, nós tava tudo sentada lá fora..." 
Quanto à concordância nominal, foram selecionados apenas sintagmas com dois elementos, pois em cada texto foram encontrados apenas dois sintagmas com mais de dois elementos ("as outra menina" e "os dois gato gêmeos")

\section{ANALISE ESTATISTICA}

\subsection{Concordância Verbal}

Os informantes masculinos, como pode ser observado no quadro abaixo, produziram concordância verbal em $57,14 \%$ dos 63 sintagmas analisados. A presença de concordância foi também predominante em cada grupo de sintagmas, com exceção do grupo onde os sujeitos eram itens lexicalizados (LEX) tais como "meus colega travessou", "umas menina aí que é legal". Neste último grupo houve 75\% de ausência de concordância. No emprego de "a gente" predominou o emprego da norma como em "a gente vai".

\begin{tabular}{|c|c|c|c|c|c|c|}
\hline \multirow[b]{2}{*}{ SUJEITO } & \multicolumn{2}{|c|}{ SINTAGMAS } & \multicolumn{2}{|c|}{ CONCORDÂNCIA } & \multicolumn{2}{|c|}{ AUSANCIA/CONCORDANCTA } \\
\hline & No & $\%$ & No & $\%$ & No & $\%$ \\
\hline Nos $\ldots \ldots \ldots \ldots$. & 25 & 39,68 & 17 & 68 & 8 & 32 \\
\hline A gente & 15 & 23,80 & 10 & 66,66 & $\mathbf{5}$ & $\mathbf{3 3 , 3 3}$ \\
\hline Eles $\ldots \ldots \ldots \ldots$ & 11 & 17,46 & 6 & $\mathbf{5 4 , 5 4}$ & 5 & 45,45 \\
\hline Lexicalizados & 12 & 19,4 & 3 & 25 & 9 & 75 \\
\hline TOTAL ...... & 63 & 100 & 46 & $\mathbf{5 7 , 1 4}$ & 27 & 42,85 \\
\hline
\end{tabular}

QUADRO NO 1 - Concordancia verbal-informantes masculinos

Nos dados produzidos pelos informantes femininos, predominou a ausência de concordância verbal em $83,69 \%$ dos 92 sintagmas analisados. A ausência de concordância só não prevaleceu nos dois sintagmas com "A GENTE" como sujeito, onde houve $100 \%$ de concordância. A diferença entre os dois grupos foi de $40,84 \%$. 


\begin{tabular}{|c|c|c|c|c|c|c|}
\hline \multirow[b]{2}{*}{ SUJEITO } & \multicolumn{2}{|c|}{ SINTAGMAS } & \multicolumn{2}{|c|}{ CONCORDANCIA } & \multicolumn{2}{|c|}{ AUSENCIA/CONCORDANCLA } \\
\hline & $\mathrm{N}$ & $\%$ & No & $\%$ & No & $\%$ \\
\hline Nós $\ldots \ldots \ldots \ldots$ & 36 & 41,30 & $\mathbf{3}$ & 7,89 & 33 & 91,66 \\
\hline A gente $\ldots . .$. & 2 & 2,17 & 2 & 100 & $\mathbf{0}$ & 0 \\
\hline Eles .......... & 30 & 38,04 & 8 & 26,66 & 22 & 73,33 \\
\hline Lexicalizados .. & 24 & 18,47 & 2 & 8,33 & 22 & 91,66 \\
\hline TOTAL $\ldots \ldots$ & 92 & 100 & 15 & 16,30 & 77 & 83,69 \\
\hline
\end{tabular}

QUADRO No 2 - Concordancia verbal-informantes femininos

\subsection{Concordância Nominal}

Como podemos observar no quadro a seguir, no item concordância nominal, os meninos se distanciaram mais das formas-padrão, mas a diferença entre os dois grupos é de apenas 2,98\%. Houve concordância nominal em 1 sintagma no grupo dos meninos e em 3 sintagmas no grupo das meninas.

\begin{tabular}{|c|c|c|c|c|c|}
\hline & \multirow[b]{2}{*}{ SINTAGMAS } & \multicolumn{2}{|c|}{ CONCORDANCIA } & \multirow{2}{*}{$\begin{array}{c}\text { AUSENCIA } \\
\text { No }\end{array}$} & \multirow{2}{*}{$\begin{array}{c}\text { DE CONCORDANCIA } \\
\%\end{array}$} \\
\hline & & No & $\%$ & & \\
\hline Meninos ....... & 72 & 1 & 1,38 & 71 & 98,61 \\
\hline Meninas ....... & 69 & 3 & 4,34 & 66 & 95,65 \\
\hline
\end{tabular}

\section{CONCLUSAO}

A diferença entre os dois grupos em termos de concordância nominal foi muito pequena e o fato de ambos superarem a marca de $90 \%$ quanto ao desvio do uso padrão leva-nos a afirmar que este não é um traço diferenciador entre os grupos. Os dados confirmam a hipótese de que a forma não-padrão de se indicar a pluralidade vem se impondo no uso da língua, privilegiando os elementos que antecedem 0 nome como sendo os marcadores de pluralidade.

Os dados relativos à concordância verbal, no entanto, foram surpreendentes e não comprovaram a hipótese levantada no início da pesquisa, pois os dois grupos apresentaram comportamento 
linguístico diferente (veja gráfico comparativo em apêndice). As meninas desviaram-se das formas de prestígio numa taxa bastante superior à dos meninos. Houve, por exemplo, seis ocorrências de "nós foi' no corpus das meninas e nenhuma no dos meninos, onde a forma "nós fomo" apareceu duas vezes.

O uso de "a gente" demonstrou ser um dado interessante. Houve quinze ocorrências de "a gente" na fala dos meninos e apenas duas na fala das meninas. Este foi o único traço que deu superioridade aos meninos em termos de desvio do registro padrão, em ocorrências como "a gente preparamo", por exemplo. Porém, o fato de termos apenas duas ocorrências na fala das meninas faz com que desprezemos este traço. Seria interessante, no entanto, pesquisar o porquê do maior uso desse pronome por parte dos meninos.

Segundo Coates (1986:161), "a linguagem é um dos meios pelo qual os indivíduos se situam no espaço social. A fala é um ato de identidade..."3 Isto pôde ser comprovado nos dados. Os grupos pesquisados não demonstraram qualquer preocupação em se identificar com as classes privilegiadas, pelo contrário, eles se utilizam de códigos diversos e criam vocábulos para serem entendidos apenas por seus pares. Houve momentos em que os grupos se utilizaram de códigos diferentes (língua do $\mathbf{P}$ entre outros) como forma de isolar a documentadora. Os meninos informaram que usam "essas línguas" quando estão no centro da cidade perto de policiais e não querem ser entendidos pelos mesmos.

Segundo Romaine (1978), vários estudos sociolingüísticos americanos comprovaram que as mulheres produzem formas mais próximas da linguagem padrão e que isto acontece porque acredita-se que as mulheres tenham maior consciência do status social e do prestígio que é associado a certas formas de linguagem. No entanto, o fato de os informantes masculinos, em nosso estudo, terem produzido uma porcentagem maior de formas padrão não nos autoriza a usar a mesma justificativa. Os dados (5 informantes masculinos e 6 femininos) são insuficientes para afirmações categóricas, porém, acreditamos que esses mesmos dados indicam que não se pode generalizar e aceitar as afirmações até então feitas de que as 
mulheres são mais sensíveis às formas de prestígio. Para fazer tal afirmação, seria necessário que a única variante entre os grupos pesquisados nos diversos estudos fosse sempre o sexo.

\section{NOTAS}

1

Since the girls did not belong to a closely-knit group and did not have a clearly defined system of cultural values, it was not possible to measure their vernacular loyalty by means of a vernacular culture index. (minha tradução)

2

Despite the development of special techniques, a linguistic investigator invariably encounters the problem which Labov has aptly named 'the observer's paradox': language in the community can be studied only by collecting large volumes of natural speech on good quality recordings; yet, a stranger who attempts to obtain these dramatically changes the character of the phenomenon he is observing. (minha tradução)

3

Language is one of the means by which individuals locate themselves in social space. Speech is an act of identity... (minha tradução)

\section{REFERENCLAS BIBLIOGRÁFICAS}

AEBISCHER, Verena \& FOREL, Claire (Org.) Falas masculinas, falas femininas? Trad. Celene M. Cruz et. al. São Paulo: Brasiliense, 1991.

CHESCHIRE, Jenny. Variations in an English dialect: $a$ sociolinguistics study. Cambridge: Cambridge University Press, 1982.

COATES, Jennifer. Women, men and language: a sociolinguistic account of sex differences in language. London: Longman, 1986.

LABOV, W. The social stratification of English in new York City. Washington D.C.: Center for Applied Linguistics, 1966.

MACAULAY, R. K. S. Variations and consistency in Glaswegian English. In: TRUDGILL, Peter (Ed.). Sociolinguistics pattern in Britain English. London: Edward Arnold, 1978. p. 132-43.

MILROY, J., MILROY, L. Belfast: change and variation in an urban vernacular. In: TRUDGILL, Peter (Ed.). Sociolinguistics pattern in Britain English. London; Edward Arnold, 1978. p. 19-36.

MILROY, Lesley. Language and social networks. Oxford: Brasil Blackwell, 1987.

TRUDGILL, Peter. The social differentiation of English in Norwich. London: Cambridge University Press, 1974. 
CONCORDÂNCIA VERBAL

GRÁFICO COMPARATIVO

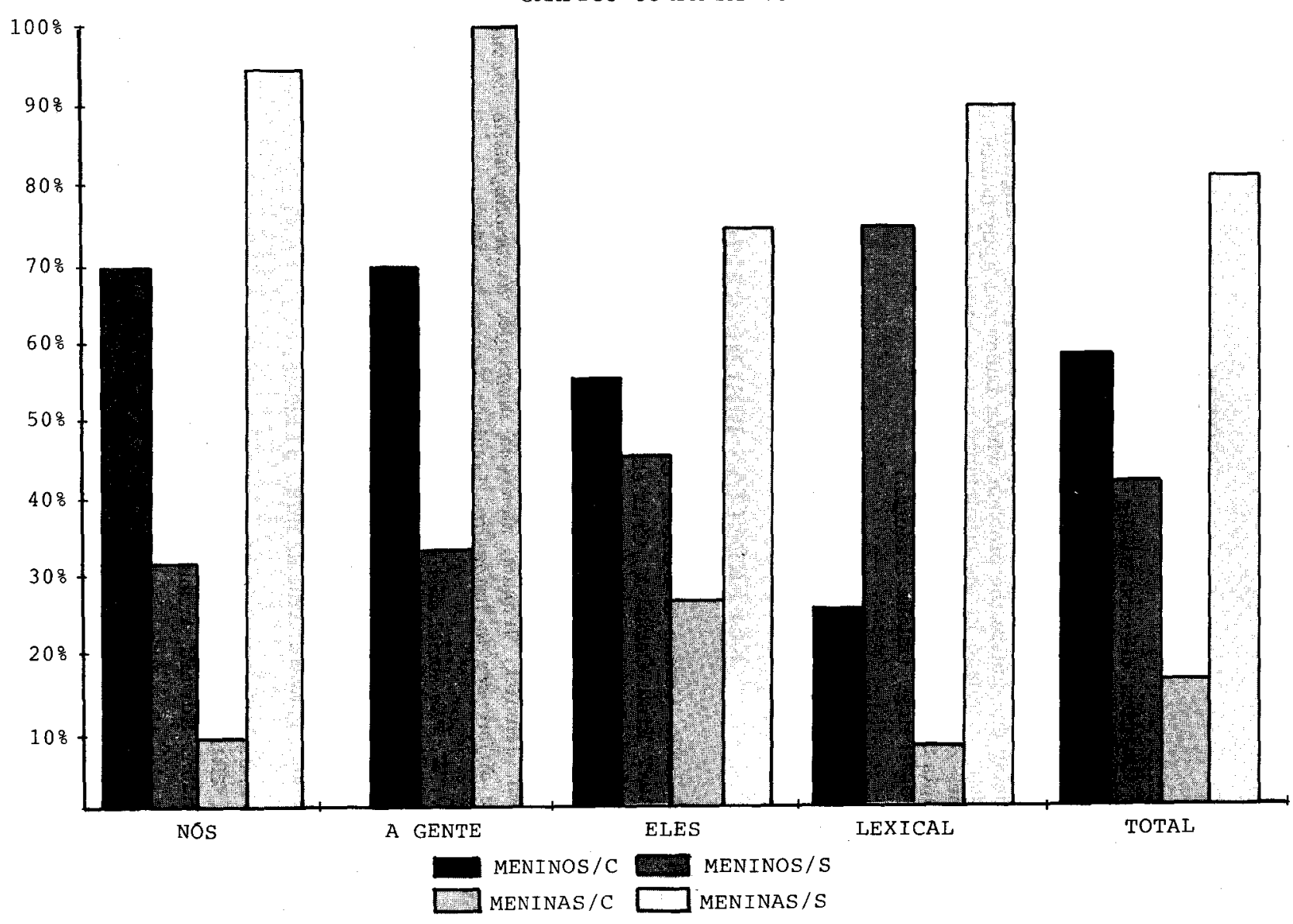

